\title{
APPLICATION UNIFORMITY OF AN IMPELLICONE ANHYDROUS AMMONIA
} MANIFOLD

\author{
H. Mark Hanna \\ Extension Ag Engineer \\ Agricultural and Biosystems Engineering Department \\ Kyle J. Baumgartner \\ Undergraduate Research Intern \\ Agricultural and Biosystems Engineering Department \\ Thomas S. Colvin \\ USDA-ARS Ag Engineer \\ USDA Soil Tilth Laboratory \\ J. L. Baker \\ Professor \\ Agricultural and Biosystems Engineering Department
}

\section{Introduction}

Since the 1960's anhydrous ammonia $\left(\mathrm{NH}_{3}\right)$ has become the most widely used source of nitrogen (N) fertilizer in agriculture. In fact over 8.1 billion pounds of $\mathrm{NH}_{3}$ is used in the United States every year (Terry and Kirby, 1997). With the cost and wide spread use of $\mathrm{NH}_{3}$ operators are seeking ways to improve uniformity and reduce rates of application. This is because most $\mathrm{NH}_{3}$ tends to be over-applied due to variability in $\mathrm{NH}_{3}$ equipment. Reducing variability will put more money into producers' pockets and reduce the likelihood of $\mathrm{N}$ leaching into water supplies. At a cost of $\$ 267 /$ ton of $\mathrm{NH}_{3}$, improved application equipment that reduced use in the United States by 5\% would result in direct savings of $\$ 65$ million annually for crop producers (Hanna et al., 2002). A key component of $\mathrm{NH}_{3}$ application equipment that affects uniformity is the distribution manifold. Tests have shown that some outlets on manifolds release two to four times as much $\mathrm{NH}_{3}$ as other outlets. Some knives could be putting on two to four times the desired rate while other knives could be putting on very little $\mathrm{NH}_{3}$ (Fee, 1999). This means that some plants may be getting more $\mathrm{N}$ than they can use and others are not getting enough $\mathrm{N}$ due to poor distribution by application equipment. In recent years, new manifolds have been tested and produced that improve uniformity among distribution ports.

One such manifold is the Vertical-Dam (Continental $\mathrm{NH}_{3}$ Products, Dallas, TX) which uses specific rings for certain applications and application rates. Vertical-Dam manifolds with 11 active outlets have produced coefficients of variation of $15 \%$ to $18 \%$ compared to conventional manifolds producing 30\% or higher coefficients of variation. However, the Vertical-Dam does have some drawbacks. Different rings and housings may be required for different types of applications. The Vertical-Dam manifolds tend to cost three to four times more than a conventional manifold. Other prototype manifolds have been developed at Iowa State University using a cone design (impellicone) to evenly distribute $\mathrm{NH}_{3}$ (Boyd et. al., 2002). 


\section{Objectives}

Testing was performed to measure and record port-to-port flow rates of $\mathrm{NH}_{3}$ during actual field application with these objectives:

1. To determine and compare the manifold distribution uniformity of a Vertical-Dam manifold, old impellicone prototype manifold, and a newer impellicone prototype manifold.

2. To evaluate the effect of various design modifications of the newer impellicone prototype on distribution uniformity.

\section{Methods and Materials}

\section{Initial test manifolds}

$\mathrm{NH}_{3}$ manifolds were set up to allow distribution through 11 outlet ports for an 11-knife applicator. A John Blue A-3300 Nitropacer (CDS John Blue Co., Huntsville, AL) $\mathrm{NH}_{3}$ regulator was used ahead of the manifolds. Nitrogen (N) was applied at $84 \mathrm{~kg} \mathrm{~N} / \mathrm{ha}$ (75 lb N/ac) and 168 $\mathrm{kg} \mathrm{N} / \mathrm{ha}$ (150 lb N/ac) rates. Both the small and large housing Vertical-Dam manifolds were used in the tests. The small housing Vertical-Dam with ring (LG 15"=155\#N/acre@6 mph: max cap. @65\% tank psi) was used for the lower application rate of $84 \mathrm{~kg} \mathrm{~N} / \mathrm{ha}$ (75 lb. N/ac). The large housing Vertical-Dam manifold with corn ring (corn 30"=75\# N min/acre @6 mph max. cap. @65\% tank psi) was used for the higher application rate of $168 \mathrm{~kg}$ N/ha (150 lb N/ac). A pipetee was used in the top of the manifold housing for holding pressure and temperature sensors. A 25.4-mm (1.0-in.) diameter 254-mm (10.0-in.) long pipe nipple with two threaded ports for pressure and temperature sensors was used to direct incoming $\mathrm{NH}_{3}$ horizontally into the manifold. An Acme $\mathrm{NH}_{3}$ fitting was used on the entry end of the pipe for attaching the regulator hose to the manifold.

The old impellicone was an original prototype of Iowa State University (Boyd et al., 2002). This manifold had 13 distribution ports. Of these ports, 11 were used for $\mathrm{NH}_{3}$ application and the other two ports were spaced out evenly and used for holding pressure and temperature sensors. A 25.4-mm (1.0-in.) diameter nipple that was 254-mm (10.0-in.) long was used with an Acme $\mathrm{NH}_{3}$ fitting at the manifold entry point. The old impellicone had a large central housing that accommodates a free-spinning cone. External spiral grooves on the cone were cut to act as a pathway for the $\mathrm{NH}_{3}$. Flow pressure causes the cone to spin, evenly spreading $\mathrm{NH}_{3}$ across the ports. The cone had 9.53-mm (0.375-in.) grooves in a spiral shape to get the desired affect.

Several subsequent versions of this design were also tested (new impellicone prototypes). Designs were based on the old impellicone design, but were smaller and more practical for commercial production. The housing had 12 outlet ports. In testing, 11 of these outlet ports were used for application and a pipe tee for temperature and pressure sensors was inserted in the $12^{\text {th }}$ port. A 25.4-mm (1.0-in.) diameter nipple 254-mm (10.0-in.) long was used for entry at the bottom of the distribution manifold body. For initial tests, a smooth flat-top lid with an o-ring seal and four allen-head screws were used to fasten the lid to the manifold housing. In the initial test, two different cones were used (figure 1). One cone had four spiral paths with 3.18-mm (0.125-in.) square grooves cut into the cone. This cone was narrower than the original cone and had a flat or blunt end. The second cone was similar, but with just three grooved spiral paths. In addition to the two cones, several objects were used above the cone to help limit upward displacement of the cone during $\mathrm{NH}_{3}$ flow. A 15.37 -mm (0.605-in.) tall and 15.88-mm (0.625-in.) diameter 
(corner to opposite corner) nut including a solid threaded shaft was used. A 25.4-mm (1.0in.) nylon plastic pipe bushing with a height of $15.37-\mathrm{mm}(0.605-\mathrm{in}$.) was used for another treatment. A nylon plastic bushing of 25.4-mm (1.0-in.) diameter with a height of 23.06- $\mathrm{mm}$ (0.908-in.) was used in another treatment and labeled as double-height bushing. Separate tests at both the high and low rates were made using the three-fluted cone and plugging distribution ports 3,6 , and 9 of consecutively numbered ports around the perimeter of the manifold.

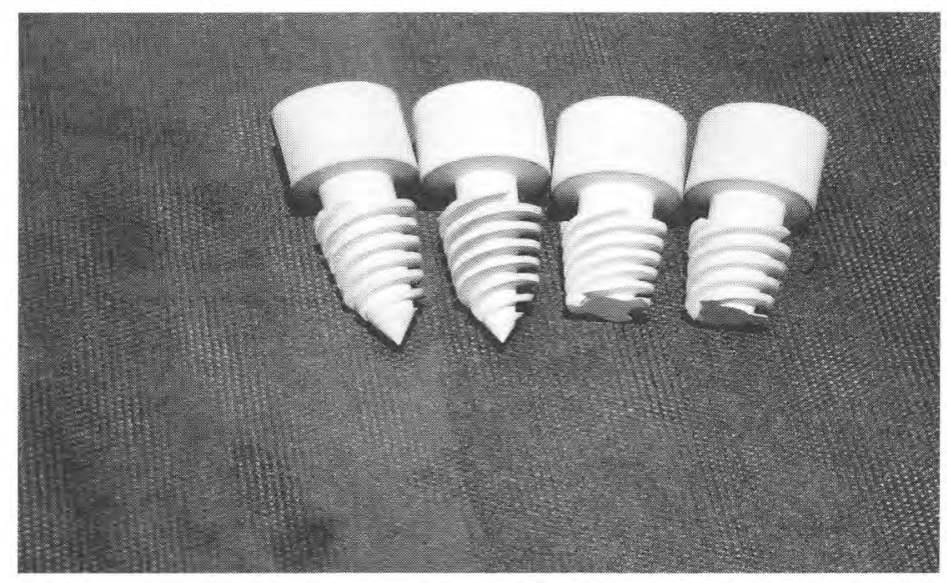

Figure 1. From left to right: shallow flute, deep flute, four-flute, and three-flute cones.

\section{Follow-up test manifolds}

A second experiment was performed using several different types of lids and cones based on performance measurements from initial tests. For this experiment the actual manifold housing was not changed. Further design modifications were tested for cones and lids. Two additional cone styles evaluated were the deep flute and shallow flute (figure 1). Both of these cones had a hole centered in the top and drilled 34.93- $\mathrm{mm}$ (1.38-in.) deep with a pointed end. The shallow fluted cone had $3.18-\mathrm{mm}(0.125$-in.) square-cut grooves cut into a spiral. The deep-fluted cone had 4.76-mm (0.188-in.) square cut grooves in a spiral. One-piece lids had spacers that fit with tight tolerances down into the manifold housing and limited the upward displacement of the cone in the manifold during $\mathrm{NH}_{3}$ flow. A shaft protruded down from the center of each lid into the cone through the hole in the top of the cone. One ball bearing was inserted into the needle to allow a surface for the shaft and cone to spin on. An exploded view of the manifold assembly is shown in figure 2. Lids with spacers of 27.56-mm (1.085-in.), 20.68-mm (0.814-in.), 18.54$\mathrm{mm}(0.730$-in.), and 16.38-mm (0.645-in.) were tested (figure 3). Some lids were tested with no ball bearing in the top of the cone. Additional N rates of $224 \mathrm{~kg} \mathrm{~N} / \mathrm{ha}$ (200lb N/ac) and $43 \mathrm{~kg}$ $\mathrm{N} / \mathrm{ha}$ (38lb N/ac) were each tested for one manifold style. 


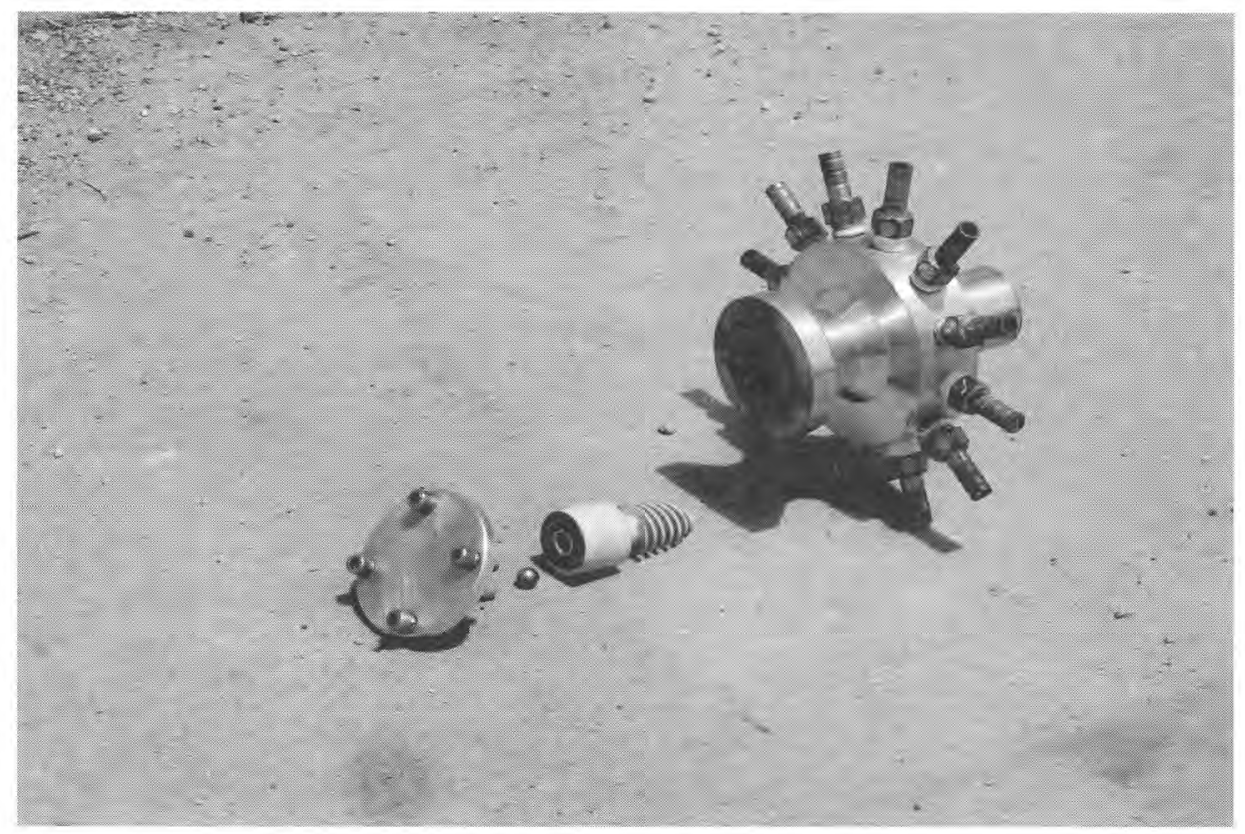

Figure 2. Exploded view of new impellicone manifold.

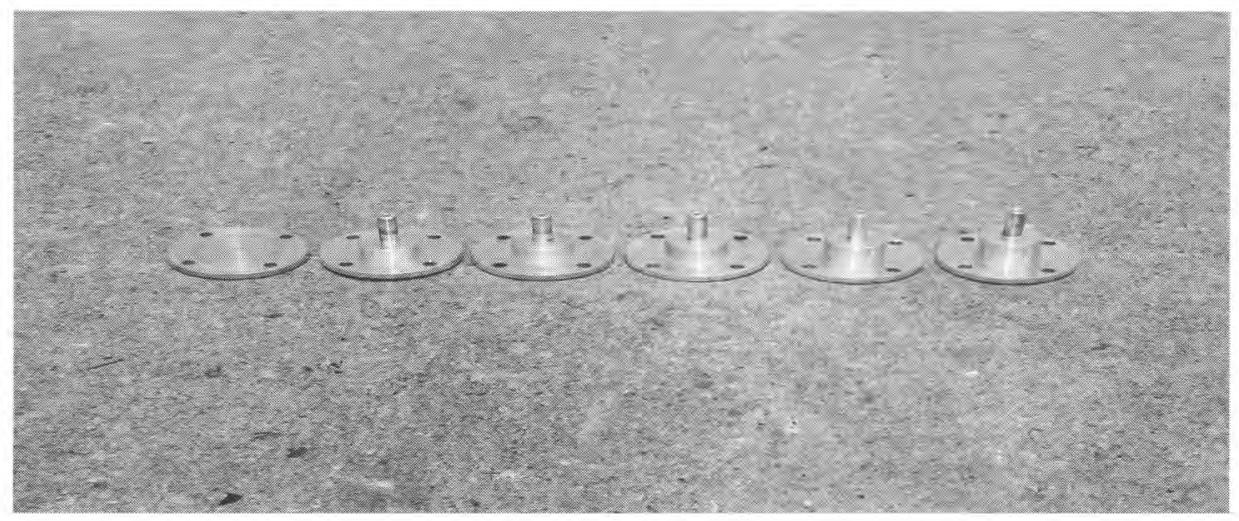

Figure 3. New impellicone lids from left to right: smooth lid, 16.38-mm (0.645-in.), 18.54-mm (0.730-in.), 20.68-mm (0.814-in.), 24.13-mm (.950-in.), (not used in this experiment), and 27.56-mm (1.085-in.) lids.

\section{Experimental design and other equipment}

A three-point hitch $\mathrm{NH}_{3}$ applicator (DMI model 3250) with 11 knives was used for application. The applicator was outfitted with a system of valves to temporarily re-direct $\mathrm{NH}_{3}$ flow from the knives into 19-L (5-gal.) collection buckets that were approximately half-full of water (Hanna et al., 2002). Valves were connected together and simultaneously opened or closed by a solenoid valve and pneumatic cylinder. Applicator travel speed was $8 \mathrm{~km} / \mathrm{h}(5 \mathrm{mi} / \mathrm{h})$. Manifold treatments were applied in three completely randomized field blocks (three replications each). Length of test plots was $67.1 \mathrm{~m}$ ( $220 \mathrm{ft}$ ). Collection times were adjusted to allow for an average of $0.5 \mathrm{~kg}(1.0 \mathrm{lb})$ of $\mathrm{NH}_{3}$ to be collected in each bucket. Collection times of 10 seconds for 224 $\mathrm{kg} \mathrm{N} / \mathrm{ha}$ (200 lb N/ac) rate, 13 seconds for $168 \mathrm{~kg} \mathrm{~N} / \mathrm{ha}$ (150 lb N/ac) rate, 25 seconds for 84 
$\mathrm{kg} \mathrm{N} / \mathrm{ha}$ (75 lb N/ac) rate, and 50 seconds for $43 \mathrm{~kg}$ N/ha (38 lb N/ac) were used. A datalogger recorder (Omega Om-3000, Stamford,CT) was used to measure and record temperature and pressure readings in the system before and after the distribution manifold. A detailed description of the application equipment can be found in Boyd et al. (2002) and Hanna et al. (2002).

Anhydrous ammonia can cause caustic burns and inhalation problems, so safety equipment was worn when working around the applicator and collection buckets. Unvented goggles, rubber gloves, and long sleeve clothing and pants were used. The valve operator wore a respirator in addition to the other safety equipment. A livestock tank full of water and water dispensers on applicator equipment were also available in case of an emergency.

\section{Calculation of data}

Several measures of uniformity were calculated from the data that were collected. The weight of $\mathrm{NH}_{3}$ released from each port was calculated by subtracting the initial weight of the water and bucket from the final weight, including $\mathrm{NH}_{3}$, after the test was completed. The average outlet difference was calculated as the average of absolute values of the differences between $\mathrm{NH}_{3}$ from each individual outlet and the mean output. The average percentage outlet difference is the average of the output differences in a percent format. The high/low ratio is the highest output weight divided by the lowest output weight. The coefficient of variation is the standard deviation of the $\mathrm{NH}_{3}$ output weights from the 11 ports, divided by the mean output, and multiplied by 100 for a percentage. Statistical analyses of variance were used to measure a $95 \%$ probability of treatment difference. Within the follow-up experiment, specific contrasts were used to test for differences between two treatments.

\section{Results and Discussion}

\section{Initial test higher rate}

As shown in table 1, at the higher $\mathrm{N}$ application rate of $168 \mathrm{~kg} \mathrm{~N} / \mathrm{ha}$ (150 lb N/ac), the new impellicone three-flute with three plugged ports had numerically the greatest uniformity in all categories of all manifolds tested. This manifold had a CV of 3.8\% with manifold pressure at $54 \%$ of tank pressure. The new impellicone prototype three-flute cone with plugged ports statistically was similar to the new impellicone three-flute manifold with nut, old impellicone, new impellicone three-flute manifold with bushing, and new impellicone three-flute with double height bushing. The new impellicone three-flute with nut had numerically the second best uniformity. This manifold was used with a manifold pressure $47 \%$ of tank pressure and had a CV of $6.2 \%$. Statistically it was also in the group with the greatest uniformity. The new impellicone three-flute manifold with bushing was numerically in the middle of the manifolds tested. This manifold produced a CV of $9.7 \%$ with manifold pressure at $50 \%$ of the tank pressure. The new impellicone protoype with bushing was statistically similar to all manifolds except for the Vertical-Dam corn ring. The Vertical-Dam manifold with corn ring had numerically the least uniformity of all manifolds for $\mathrm{CV}$, average percent outlet difference, high/ low ratio, and average absolute difference. The Vertical-Dam with corn ring had a CV of $15.6 \%$ with a manifold pressure $47 \%$ of tank pressure. Statistically the Vertical-Dam with corn ring was similar to the new impellicone with three-flutes, new impellicone with four-flutes, and new 
Table 1. Tank and manifold pressure, application rate, and distribution of various manifolds during initial test.

\begin{tabular}{|c|c|c|c|c|c|c|c|c|}
\hline Treatment & Tank Pressure & $\begin{array}{l}\text { Pressure before } \\
\text { manifold }\end{array}$ & $\begin{array}{l}\text { Pressure after } \\
\text { manifold }\end{array}$ & $\mathrm{N}$ application rate & $\begin{array}{l}\text { Avg. outlet } \\
\text { difference, } \\
\mathrm{NH} 3\end{array}$ & $\begin{array}{l}\text { Avg. \% outlet } \\
\text { difference }\end{array}$ & $\begin{array}{l}\text { High/low } \\
\text { ratio }\end{array}$ & $\begin{array}{l}\text { Coefficient of } \\
\text { variation } \%\end{array}$ \\
\hline & $\mathrm{kPa}(\mathrm{psi})$ & $\mathrm{kPa}(\mathrm{psi})$ & $\mathrm{kPa}(\mathrm{psi})$ & $\mathrm{kg} / \mathrm{ha}(\mathrm{lb} / \mathrm{ac})$ & $\mathrm{kg}(\mathrm{lb})$ & & & \\
\hline \multicolumn{9}{|l|}{$84 \mathrm{~kg}$ N/ha (75 lb N/ac) } \\
\hline Vertical Dam (SH) & $655(95)$ & $345(50.0)$ & $324(47.0)$ & $90(80)$ & $0.056(0.124) b_{c d}^{*}$ & $12.2 \mathrm{~cd}$ & $1.66 \mathrm{bcd}$ & $15.5 \mathrm{bcde}$ \\
\hline Old Impellicone & $682(99)$ & $241(35.3)$ & $202(29.3)$ & $98(87)$ & $0.036(0.079) a b$ & $7.1 \mathrm{a}$ & $1.37 \mathrm{a}$ & $8.9 a$ \\
\hline New Impellicone 3 flute & $613(89)$ & $184(26.7)$ & $165(24.2)$ & $95(85)$ & $0.052(0.115) \mathrm{bcd}$ & $10.6 \mathrm{bcd}$ & $1.83 \mathrm{de}$ & $14.8 \mathrm{bcd}$ \\
\hline New Impellicone 4 flute & $689(100)$ & $212(30.7)$ & $184(26.7)$ & $89(80)$ & $0.071(0.157) \mathrm{d}$ & $15.6 \mathrm{e}$ & $2.07 \mathrm{e}$ & $23.5 \mathrm{~g}$ \\
\hline New Impellicone 3 flute with nut & $724(105)$ & $254(36.8)$ & $203(29.5)$ & $90(81)$ & $0.042(0.093) a b c$ & $8.8 \mathrm{ab}$ & $1.41 \mathrm{ab}$ & $11.0 \mathrm{ab}$ \\
\hline New Impellicone 3 flute with bushing & $744(108)$ & $262(38.0)$ & $221(32.0)$ & $98(87)$ & $0.049(0.108) b c$ & $9.7 \mathrm{bc}$ & $1.43 \mathrm{abc}$ & $11.5 a b c$ \\
\hline $\begin{array}{l}\text { New Impellicone } 3 \text { flute double height } \\
\text { bushing }\end{array}$ & $675(98)$ & $358(52.0)$ & $218(31.7)$ & $88(79)$ & $0.062(0.138) \mathrm{cd}$ & $13.7 \mathrm{~d}$ & $1.78 \mathrm{bcde}$ & $17.0 \mathrm{cdef}$ \\
\hline $\begin{array}{l}\text { New Impellicone } 3 \text { flute with } 3 \text { plugged } \\
\text { ports }\end{array}$ & $689(100)$ & $241(35.3)$ & $223(32.3)$ & $85(76)$ & $0.023(0.051) \mathrm{a}$ & $5.1 \mathrm{a}$ & $1.23 \mathrm{a}$ & $6.6 \mathrm{a}$ \\
\hline \multicolumn{9}{|l|}{$168 \mathrm{~kg} \mathrm{~N} / \mathrm{ha}(150 \mathrm{lb} \mathrm{N} / \mathrm{ac})$} \\
\hline Vertical Dam (corn ring) & $682(99)$ & $336(48.7)$ & $322(46.7)$ & $176(157)$ & $0.058(0.128) \mathrm{c}$ & 12.31 & $1.72 \mathrm{~d}$ & $15.6 \mathrm{~d}$ \\
\hline Old Impellicone & $682(99)$ & $379(55.0)$ & $324(47.0)$ & $185(165)$ & $0.026(0.058) a b$ & $5.3 \mathrm{ab}$ & $1.29 \mathrm{ab}$ & 7.1ab \\
\hline New Impellicone 3 flute & $613(89)$ & $317(46.3)$ & $288(42.0)$ & $179(160)$ & $0.041(0.092) b c$ & $8.7 \mathrm{bcdef}$ & 1.49abcd & $11.6 \mathrm{bcd}$ \\
\hline New Impellicone 4 flute & $646(94)$ & $322(46.7)$ & $296(43.0)$ & $169(151)$ & $0.037(0.083) b c$ & $8.4 \mathrm{bcde}$ & $1.44 \mathrm{abcd}$ & $11.7 \mathrm{bcd}$ \\
\hline New Impellicone 3 flute with nut & $724(105)$ & $436(63.3)$ & $356(51.7)$ & $184(165)$ & $0.025(0.056) a b$ & $5.2 \mathrm{a}$ & $1.20 \mathrm{a}$ & $6.2 \mathrm{a}$ \\
\hline New Impellicone 3 flute with bushing & $744(108)$ & $422(61.3)$ & $372(54.0)$ & $195(174)$ & $0.042(0.094) b c$ & $8.2 \mathrm{bcd}$ & $1.34 a b c$ & $9.7 \mathrm{abc}$ \\
\hline $\begin{array}{l}\text { New Impellicone } 3 \text { flute double height } \\
\text { bushing }\end{array}$ & $675(98)$ & $501(72.7)$ & $342(49.7)$ & $174(155)$ & $0.034(0.076) \mathrm{ab}$ & $7.4 \mathrm{bc}$ & $1.42 \mathrm{abcd}$ & 9.8abcd \\
\hline $\begin{array}{l}\text { New Impellicone } 3 \text { flute with } 3 \text { plugged } \\
\text { ports }\end{array}$ & $689(100)$ & $395(57.3)$ & $374(54.3)$ & $206(184)$ & $0.016(0.035) \mathrm{a}$ & $2.9 \mathrm{a}$ & $1.12 \mathrm{a}$ & $3.8 \mathrm{a}$ \\
\hline
\end{tabular}

* Treatment values within each column followed by a different letter are statistically different at a $95 \%$ confidence level 
impellicone with double height bushing manifolds. All of the manifolds produced lower CV's at the higher rate application except for the Vertical-Dam corn ring. The Vertical-Dam corn ring had only a slight CV increase of $0.1 \%$.

\section{Initial test lower rate}

The manifold with the most uniformity at the lower application rate was the new impellicone prototype with a three-flute cone and three evenly plugged ports at the distribution outlets (table 1). This manifold produced a $6.6 \% \mathrm{CV}$ while being tested at a manifold pressure $32 \%$ of tank pressure. The CV for this manifold was numerically better than all other manifolds tested at the lower application rate, but was statistically the same as the old impellicone, new impellicone with nut, and new impellicone with bushing manifolds. The new impellicone manifold with the most uniformity excluding the three-flute plugged-port manifold, was the new impellicone three-flute with nut. This manifold produced an $11.0 \% \mathrm{CV}$ with a manifold pressure $28 \%$ of the tank pressure. The new impellicone manifold with a three-flute cone with nut was statistically similar to all of the manifolds except the new impellicone four-flute and new impellicone threeflute cone with double-height bushing manifolds. The Vertical-Dam small housing manifold numerically had the next to lowest uniformity with a CV of $15.5 \%$ with a manifold pressure at $50 \%$ of tank pressure. The Vertical-Dam small housing manifold was statistically no different than other versions of the new impellicone manifold with three flutes and using 11 outlets. The new impellicone prototype with a four-flute cone had the lowest uniformity at the $34 \mathrm{~kg}$ $\mathrm{N} / \mathrm{ha}(75 \mathrm{lb} \mathrm{N} / \mathrm{ac}$ ) rate. The four-flute cone, while operating at a manifold pressure $27 \%$ of tank pressure, had a coefficient of variation (CV) of $23.5 \%$. The four-flute cone was statistically different and numerically higher than all other manifolds.

\section{Follow-up test higher rate}

As shown in table 2 the best performing manifold as indicated by low CV, high/low ratio, and average percent outlet difference was the new impellicone prototype three-flute and smooth lid. This manifold produced an average CV of $8.7 \%$ with manifold pressure $44 \%$ of tank pressure. This manifold was tested in initial tests and produced a CV of $11.6 \%$. The second best performing manifolds were the new impellicone deep flute with $18.5-\mathrm{mm}(0.730-\mathrm{in}$.) with and without ball bearing. These two manifolds produced identical CV's of $9.3 \%$ and statistically there was no significant difference in application uniformity among other measurements. The deep flute $18.5-\mathrm{mm}(0.730$-in.) lid was tested with a manifold pressure $49 \%$ of tank pressure and the 18.5-mm (0.730-in.) lid with no ball bearing was tested with a manifold pressure $43 \%$ of tank pressure. The manifold with the lowest uniformity was the Vertical-Dam corn ring manifold. The Vertical-Dam corn ring manifold produced a CV of $16.1 \%$ while manifold pressure was $40 \%$ of tank pressure. This CV was slightly higher than the CV of $15.6 \%$ in the initial test. Statistically the new impellicone deep flute prototype with $18.5-\mathrm{mm}(0.730$-in.) lid with no ball bearing had a lower absolute difference, percentage difference, hi/low ratio, and CV than VerticalDam treatments with a $99 \%$ confidence level. The second highest CV was produced by the new impellicone shallow flute manifold with 20.7-mm (0.814-in.) lid. This manifold had a $12.9 \%$ CV while at a manifold pressure $45 \%$ of tank pressure. The deep-fluted cone statistically had a lower absolute difference, percentage difference, and CV than shallow fluted cones at the $168 \mathrm{~kg}$ N/ha (150 lb N/ac) application rate with a 95\% confidence level and a lower high/low ratio at a 90\% confidence level. 
Table 2. Tank and manifold pressure, application rate, and distribution of various manifolds during follow-up test.

\begin{tabular}{|c|c|c|c|c|c|c|c|c|}
\hline Treatment & $\begin{array}{l}\text { Tank } \\
\text { Pressure }\end{array}$ & $\begin{array}{l}\text { Pressure } \\
\text { before } \\
\text { manifold }\end{array}$ & $\begin{array}{l}\text { Pressure after } \\
\text { manifold }\end{array}$ & $\begin{array}{l}\mathrm{N} \text { application } \\
\text { rate }\end{array}$ & $\begin{array}{l}\text { Avg. outlet } \\
\text { difference, } \\
\mathrm{NH} 3\end{array}$ & $\begin{array}{l}\text { Avg. \% outlet } \\
\text { difference }\end{array}$ & $\begin{array}{l}\text { High/low } \\
\text { ratio }\end{array}$ & $\begin{array}{c}\text { Coefficient } \\
\text { of variation } \\
\%\end{array}$ \\
\hline & $\mathrm{kPa}(\mathrm{psi})$ & $\mathrm{kPa}(\mathrm{psi})$ & $\mathrm{kPa}(\mathrm{psi})$ & $\mathrm{kg} / \mathrm{ha}(\mathrm{lb} / \mathrm{ac})$ & $\mathrm{kg}(\mathrm{lb})$ & & & \\
\hline \multicolumn{9}{|l|}{$84 \mathrm{~kg} \mathrm{~N} / \mathrm{ha}(75 \mathrm{lb} \mathrm{N} / \mathrm{ac})$} \\
\hline Vertical Dam (SH) & $1000(145)$ & $494(71.4)$ & $455(66.0)$ & $98(87)$ & $0.072(0.160)$ & 14.3 & 1.78 & 18.6 \\
\hline Deep flute .814" lid & $821(119)$ & $330(47.8)$ & $227(32.9)$ & $101(90)$ & $0.045(0.101)$ & 8.8 & 1.36 & 10.4 \\
\hline Deep flute $.730 "$ lid & $821(119)$ & $310(44.9)$ & $229(33.2)$ & $101(90)$ & $0.028(0.063)$ & 5.5 & 1.32 & 8.0 \\
\hline Deep flute $.645^{\prime \prime}$ lid & $841(122)$ & $301(43.7)$ & $241(35.0)$ & $98(86)$ & $0.027(0.059)$ & 5.4 & 1.23 & 6.8 \\
\hline New Impellicone 3 flute & $869(126)$ & $261(37.8)$ & $235(34.1)$ & $99(88)$ & $0.053(0.118)$ & 10.7 & 1.54 & 13.2 \\
\hline Deep flute $.730 "$ lid no bearing & $952(138)$ & $281(40.7)$ & $239(34.7)$ & $101(90)$ & $0.043(0.095)$ & 8.3 & 1.33 & 9.7 \\
\hline \multicolumn{9}{|l|}{$168 \mathrm{~kg} \mathrm{~N} / \mathrm{ha}(150 \mathrm{lb} \mathrm{N} / \mathrm{ac})$} \\
\hline Vertical Dam (corn ring) & $1000(145)$ & $432(62.7)$ & $400(58.0)$ & $172(153)$ & $0.059(0.132)$ & 13.1 & 1.66 & 16.1 \\
\hline Shallow flute $.814 "$ lid & $979(142)$ & $496(71.9)$ & $444(64.4)$ & $178(159)$ & $0.050(0.110)$ & 10.4 & 1.54 & 12.9 \\
\hline Shallow flute $1.085 " \mathrm{lid}$ & $979(142)$ & $594(86.1)$ & $463(67.1)$ & $178(159)$ & $0.040(0.088)$ & 8.3 & 1.37 & 10.0 \\
\hline Shallow flute $645^{\prime \prime}$ lid & $986(143)$ & $489(70.9)$ & $448(64.9)$ & $182(162)$ & $0.045(0.100)$ & 8.0 & 1.47 & 10.8 \\
\hline Deep flute $1.085^{\prime \prime} \mathrm{lid}$ & $1014(147)$ & $770(111.7)$ & $421(61.1)$ & $176(157)$ & $0.034(0.076)$ & 7.3 & 1.42 & 9.8 \\
\hline Deep flute $645 " \mathrm{lid}$ & $1020(148)$ & $546(79.2)$ & $451(65.4)$ & $183(163)$ & $0.040(0.089)$ & 8.1 & 1.38 & 10.0 \\
\hline Deep flute $814 " \mathrm{lid}$ & $960(139)$ & $592(85.8)$ & $437(63.4)$ & $172(153)$ & $0.034(0.075)$ & 7.5 & 1.39 & 9.7 \\
\hline Deep flute $.730 " \mathrm{lid}$ & $841(122)$ & $523(75.9)$ & $412(59.8)$ & $188(167.8)$ & $0.037(0.083)$ & 7.4 & 1.39 & 9.3 \\
\hline New Impellicone 3 flute & 869 (126) & $416(60.4)$ & $386(56.0)$ & $182(162)$ & $0.033(0.074)$ & 6.9 & 1.32 & 8.7 \\
\hline Deep flute $.730 "$ lid no bearing & $869(126)$ & $434(63.0)$ & $373(54.1)$ & $174(155)$ & $0.033(0.074)$ & 7.3 & 1.35 & 9.3 \\
\hline \multicolumn{9}{|l|}{$224 \mathrm{~kg}$ N/ha (200 lb N/ac) } \\
\hline Deep flute .730 " lid no bearing & $1032(150)$ & $602(87.3)$ & $551(58.0)$ & $241(215)$ & $0.023(0.051)$ & 4.62 & 1.24 & 6.1 \\
\hline \multicolumn{9}{|l|}{ 43kg N/ha (38 lb N/ac) } \\
\hline Deep flute $.730 "$ lid no bearing & $1048(152)$ & $139(20.1)$ & $114(16.5)$ & $49(44)$ & $0.071(0.158)$ & 14.02 & 1.70 & 16.7 \\
\hline
\end{tabular}




\section{Follow-up test lower rate}

The lower $84 \mathrm{~kg}$ N/ha (75 lb N/ac) application rate was tested only with a deep fluted cone for the redesigned manifolds. The new impellicone prototype with deep-fluted cone and 16.4mm (0.645-in.) lid had the lowest CV for all manifolds tested at the $84 \mathrm{~kg} \mathrm{~N} / \mathrm{ha}$ (75 lb N/ac) application rate. This manifold produced a CV of $6.8 \%$ with manifold pressure $29 \%$ of tank pressure. The 16.4-mm (0.645-in.) lid treatment also produced the lowest average percent outlet difference at $5.4 \%$ and the lowest high/low ratio at 1.23 . The manifold with the next best uniformity was the new impellicone deep-fluted cone with 18.5-mm (0.730-in.) lid. This manifold was tested with a manifold pressure $28 \%$ of tank pressure and had a CV of $8.0 \%$. The Vertical-Dam small housing produced the highest CV of manifolds tested at the $84 \mathrm{~kg}$ N/ha (75 lb N/ac) application rate. The Vertical-Dam small housing manifold had a CV of $18.6 \%$ with manifold pressure $46 \%$ of tank pressure. The Vertical-Dam small housing had numerically the highest average percent outlet difference and high/low ratio. The CV for the Vertical-Dam small housing manifold in initial tests was $15.5 \%$, but was slightly higher in follow-up tests (18.6\%). The second highest CV was for the new impellicone with three-flute cone and smooth lid. Values from the treatment of the new impellicone three-flute with smooth lid were used as a comparison with the earlier tests of this same manifold. This manifold produced a CV of 13.2\% in follow-up tests compared to a CV of $14.8 \%$ when tested initially. As a whole (when tested by statistical contrast) the new impellicone manifolds had lower absolute differences, percentage differences, high/low ratio, and CV's than the Vertical-Dam treatments with a 99\% confidence level.

\section{Follow-up extreme rates}

Tests were also conducted at $224 \mathrm{~kg} \mathrm{~N} / \mathrm{ha}$ (200 lb N/ac) and $43 \mathrm{~kg}$ N/ha (38 lb N/ac) application rates (table 2). A new impellicone deep fluted cone with 18.5-mm (0.730-in.) lid and no bearing manifold was the one used for both application rates. The manifold had a CV of $6.1 \%$ with manifold pressure 39\% of tank pressure at the $224 \mathrm{~kg} \mathrm{~N} / \mathrm{ha}$ (200 lb N/ac) rate. This CV is lower than all other treatments in the follow-up test and in the low rate of the initial test. The new impellicone deep fluted cone with a 18.5 -mm (0.730-in.) lid and no bearing manifold produced an average CV of $16.7 \%$ with manifold pressure only $10.9 \%$ of tank pressure at the extreme low rate of $43 \mathrm{~kg} \mathrm{~N} / \mathrm{ha}$ (38 lb N/ac). The $\mathrm{CV}$ for the extreme low rate had the second lowest uniformity of the low rate follow-up test.

\section{Temperatures and Pressures}

Pressure was recorded at the $\mathrm{NH}_{3}$ nurse tank, between the regulator and manifold, and at the manifold. These pressures were important in determining the percentage of tank pressure at which the manifold was operating. Temperature sensors during the experiment produced unreliable results and were excluded as a result.

\section{Conclusions}

Uniformity of thirty-four different $\mathrm{NH}_{3}$ manifold treatments was measured during initial and follow-up experiments. These manifolds included the Vertical-Dam, old impellicone manifold, and various new prototype versions of this manifold. These new impellicone manifolds had a wide variety of lids, distributing cones, and spacers. 


\section{Initial test}

Overall a new impellicone manifold using a three-flute cone design and having three evenly spaced ports plugged had the most uniformity. It produced the lowest CV's during the initial tests, 3.8\% CV for $168 \mathrm{~kg} \mathrm{~N} / \mathrm{ha}(150 \mathrm{lb} \mathrm{N} / \mathrm{ac}$ ) and $6.6 \%$ for $84 \mathrm{~kg} \mathrm{~N} / \mathrm{ha}$ (75 lb N/ac) application rates. At the $168 \mathrm{~kg} \mathrm{~N} / \mathrm{ha}$ ( $150 \mathrm{lb} \mathrm{N} / \mathrm{ac}$ ) rate the Vertical-Dam manifold had the least uniformity as it produced the highest $\mathrm{CV}$ of $15.6 \%$. At the $84 \mathrm{~kg} \mathrm{~N} / \mathrm{ha}$ (75 lb N/ac) application rate the new impellicone four-flute manifold had the least uniformity (highest CV of 23.5\%). Experiments done during initial tests indicated some manifolds with high uniformity at one rate but low uniformity at the other rate.

\section{Follow-up test}

After revisions were made to new impellicone manifolds based on results of the initial test, the manifolds had generally better uniformity. Manifolds in the follow-up test had a built-in shaft and ball bearing to reduce friction and wear on the cone. The new impellicone three-flute cone with smooth lid had the greatest uniformity (lowest CV of 8.7\%) at the $168 \mathrm{~kg} \mathrm{~N} / \mathrm{ha}$ (150 lb $\mathrm{N} / \mathrm{ac}$ ) application rate. The new impellicone deep flute with 16.4-mm (0.645-in.) lid had the most uniformity (lowest CV of 6.8\%) for the $84 \mathrm{~kg} \mathrm{~N} / \mathrm{ha}$ (75 lb N/ac) rate. The Vertical-Dam manifold had the least uniformity at both application rates (16.1\% CV at $168 \mathrm{~kg} \mathrm{~N} / \mathrm{ha}$ (150 $\mathrm{lb} \mathrm{N} / \mathrm{ac}$ ) and $18.6 \% \mathrm{CV}$ at $84 \mathrm{~kg} \mathrm{~N} / \mathrm{ha}(75 \mathrm{lb} \mathrm{N} / \mathrm{ac})$ ). Based on statistical contrasts the new impellicone treatments had a lower absolute difference, percentage outlet difference, high/low ratio, and CV than the Vertical-Dam manifold in the follow-up test. Deep fluted cones used in the new impellicone manifolds had better uniformity than shallow fluted cones. There was no statistically significant difference in application uniformity whether or not a ball bearing was used during testing of the new impellicone with deep fluted cone and 18.5-mm (0.730-in.) lid.

\section{Overall conclusions}

Several new impellicone prototype models hold promise for improving application uniformity from manifolds. In particular new impellicone manifolds with the 16.4-mm (0.645-in.), 18.5$\mathrm{mm}(0.730$-in.), and 18.5-mm (0.730-in.) with no ball bearing lids produced CV's of $10 \%$ or less for both $84 \mathrm{~kg} \mathrm{~N} / \mathrm{ha}$ (75 lb N/ac) and $168 \mathrm{~kg}$ N/ha (150 lb N/ac) application rates. With variation below 10\%, N will be more uniformly distributed across the field allowing application rates to be reduced while still supplying a minimum level of $\mathrm{N}$ to the crop.

\section{References}

Boyd, P.M. 2002. Evaluation and design of anhydrous ammonia manifolds and application variation effects on corn yields. Ph.D. dissertation, Iowa State University.

Fee, R. 1999. Fine-tuning N will be good for pocketbook and environment. Successful Farming 97 (10): 25-30.

Hanna, H. M., M. L. White, T. S. Colvin, and J. L. Baker. 2002. Anhydrous ammonia distribution during field application. Applied Engineering in Agriculture 18(4): 56-64

Terry, D. L., and B. J. Kirby. 1997. Commercial fertilizers 1997. Association of American Plant Food control Officials. Univ. of Kentucky, Lexington, Ky. 